\title{
S27-04
}

\section{THE ROLE OF INTUITION AND PROGNOSTIC RISK ASSESSMENT REGARDING THE LEAVE OF OFFENDERS WITH MENTAL DISORDERS}

\section{Schmitt}

Klinik Nette-Gut for Forensic Psychiatry, Weißenthurm, Germany

The granting of leave during terms of imprisonment plays an important part in the treatment of mentally ill offenders. According to German law, leave is to be granted in those cases where the abuse of this privilege or an attempt to flee can be negated. These regulations also, however, imply that the risk assessment of a patient's offence-related recidivism can not be the only criterion for the granting of leave.

So far, there have only been few studies about the prognostic risk assessment of the general abuse of leave. This is rather astonishing, as the granting of leave outside the institutional grounds, in particular, is a decision which often leaves those responsible fraught with anxiety. Furthermore, the abuse of a granted temporary release can lead to severe consequences on various levels.

As part of a study to be conducted in the German state of Rhineland-Palatinate, decisions about granting leave are to be analyzed and possible predictors of the abuse of leave are to be examined.

It is assumed that the abuse of leave is likely to be motivated by the conditions of particular situations and can primarily be explained by normal psychological factors.

However, it should be pointed out that, as the abuse of leave is such a rare occurrence, it poses a significant methodological problem. The criterion to be examined therefore needs to be exactly defined and particular attention must be paid to achieve an adequately high interreliability of the decision makers. 